\title{
Comentario al texto, La mirada antropológica de María Eugenia Bozzoli 1960-1985, Editorial EUNED. Autoras Olga Echeverría Murray y Margarita Bolaños Arquín
}

\author{
Ana C. Arias
}

Profesora jubilada, Escuela de Antropología, Universidad de Costa Rica, San José, Costa Rica ana.ariasquiros@gmail.com

Debo indicar que leí con interés, cuidado y entusiasmo la obra escrita por dos colegas antropólogas, pero sobre todo elaborada por dos amigas, dos personas muy queridas y cercanas con quienes he compartido experiencias, luchas, desencuentros y, ante todo, un gran respeto y consideración. Necesito señalar también que ambas, muy distintas entre sí, pero muy cercanas entre sí, siempre se caracterizaron, en el marco del entonces Departamento de Antropología de la Escuela de Antropología y Sociología, por un compromiso disciplinario y social a toda prueba; excelentes docentes que siempre buscaron una mejor preparación académica, nuevos horizontes en el dominio de la investigación antropológica y, desde luego, siempre desarrollaron una práctica política en el marco de la beligerancia, con respeto y tolerancia hacia formas de pensar y de actuar diferentes. Asimismo, promovieron y trabajaron arduamente en lo relativo al desarrollo de la antropología centroamericana y regional, a partir de encuentros, talleres y congresos. De igual forma, estimularon y fueron protagonistas de los procesos de autoevaluación y autoregulación que tuvimos en la Unidad Académica; las diferentes reformas curriculares pasaron por sus manos y por su pensamiento. Por estos motivos, siempre las recuerdo, solícitas, de un muy buen carácter, fuerte, pero respetuoso y tolerante. Sus alumnos siempre les calificaron excelentemente y estoy segura que se les

Cuadernos de Antropología

Enero-Junio 2016, 26(1), 161-164

Revista del Laboratorio de Etnología María Eugenia Bozzoli Vargas

Escuela de Antropología, Universidad de Costa Rica

http://revistas.ucr.ac.cr/index.php/antropologia

ISSN 2215-356X 
recuerda con aprecio, de espíritu inquieto ambas; de formas un tanto diferentes acometieron la necesidad de sistematizar, reflexionar y dar a conocer la historia de la antropología nacional y regional a las nuevas y viejas generaciones, objetivo que se cumple, justamente, en la obra que hoy comentamos.

Esta obra acerca de la trayectoria intelectual, docente y social de la profesora Emérita María Eugenia Bozzoli Vargas se enmarca dentro de esos intereses que mencionamos. En 464 páginas se nos presenta un texto introductorio, un telón de fondo como lo es la dinámica social de nuestro país y de la región, una valoración crítica de los aportes teórico-metodológicos y datos sustantivos de la obra de doña María Eugenia y la sistematización de 18 trabajos escritos en diferentes momentos por la autora estudiada y analizada; estos son ordenados por categorías temáticas (ARQUEOLOGÍA RURAL URBANO-MEDIOAMBIENTE, CONCEPCIONES SIMBÓLICAS-MEDICINA TALAMANQUEÑA). Se acompaña la edición con fotografías de un interés mayor por los contextos en los cuales se muestra a la autora y por personas que de una u otra forma le acompañan, gratísimo ver en ellas a los profesores Carlos H. Aguilar P. y José Antonio Camacho Zamora, ambos de grata memoria, Claudine Van Ghysem, Oscar Fonseca Zamora, entre otros.

El texto comentado se puede decir que es estrictamente académico, con pinceladas caracterizadas por un tono cercano y cariñoso sobre la autora, y esto es lógico pues a ambas profesionales les une una sólida y linda amistad con doña María Eugenia. Echando mano de un lenguaje experto, se tuvo el cuidado y la deferencia de presentarlo de una manera amena, cercana, lo que posibilitará su lectura a personas interesadas en el tema, pero no necesariamente especialistas. El tema central es, desde luego, la creación intelectual de doña María Eugenia, se hace referencia al pensamiento social y a las condiciones socioculturales imperantes en esos momentos históricos, sin olvidar los referentes teórico-metodológicos utilizados por la autora, influencias recibidas y su formación tanto en la universidad de Kansas como en la de Georgia. El texto narra, expone, describe y analiza el pensamiento antropológico y sociológico de la época y cómo este fue traducido en las investigaciones desarrolladas y cómo se fue modelando su orientación y práctica política. Alusiones al pensamiento teórico de Franz Boas, B. Malinowski, Ruth Benedict, Margareth Mead, Ralph Linton, Abraham Kardiner, Robert Lowie, Alfred Kroeber, George Murdock, y desde luego el tutor de la formación de doña María Eugenia, el Dr. Carlyle Smith; y el conocer la obra de Duncan Strong, Robert Redfield, Julian Steward, Oscar Lewis, entre muchos mas. El texto nos plantea una estructura retórica rica en figuras, fotografías, citas textuales, insinuaciones propias de las autoras del libro que nos dan como resultado esta publicación, seria, sistemática y con un estilo propio de las profesoras Echeverría y Bolaños. Debo indicar que valoro mucho la intertextualidad utilizada, pues la obra nos ofrece citas textuales y referencias a otros autores y autoras en cantidad y calidad justas; no hay un uso excesivo de textos que muchas veces nos pierden un tanto en lo referente a los puntos de vista de las escritoras y escritores de las obras.

Como queda claro en las páginas iniciales, este es el resultado del proyecto de investigación que en el 2004 se presentó a la Vicerrectoría de Investigación de la Universidad de Costa Rica, con el objetivo de rendir un homenaje a los pioneros de la formación antropológica en el país, Carlos H. Aguilar P. y María 
Eugenia Bozzoli Vargas, al sistematizar, valorar y dar a conocer parte de su obra inédita o poco conocida, los resultados fueron muy importantes, parte de ellos es la obra que hoy comentamos.

Como arqueóloga, no me puedo negar la gran oportunidad de comentar, con todo respeto, acerca de los seis textos que aparecen en el apartado, desde luego por cercanía disciplinaria y porque me evocan con toda claridad los trabajos de mi maestro don Carlos H. Aguilar P., en los seis artículos presentados por las autoras bajo la categoría de Arqueología, elaborados por doña María Eugenia en diferentes momentos de las décadas del sesenta y setenta del siglo pasado.

La autora presenta estos escritos como "informes" y siempre agradece a las instituciones que de una u otra forma colaboraron para hacer posible su ejecución y su publicación, el Instituto Geográfico Nacional, la Universidad de Costa Rica, entre otras. Los textos se caracterizan por descripciones exhaustivas de los contextos y de la evidencia arqueológica recobrada, acción propia del modelo teórico denominado histórico-cultural, en el cual la descripción de la cultura material, el método inductivo, las ubicaciones cronológicas y el concepto normativo de cultura eran centrales, dibujos, fotografías, planos y cuadros que complementan lo anterior. Se habla de las filiaciones culturales posibles de esa evidencia al fundamentarse en trabajos como los de Samuel K. Lothrop, y se esbozan apreciaciones acerca de las relaciones posibles con una región arqueológica $\mathrm{u}$ otra.

De igual manera, quiero llamar la atención acerca del trabajo denominado "La Arqueología en Costa Rica", notas de clase de los años sesenta. Aquí se habla con toda claridad acerca de la diferencia entre huaquerismo y arqueología científica, la posibilidad de que los diseños ancestrales sean la base para creaciones artísticas o artesanales; asimismo, se menciona la necesidad de que los sitios arqueológicos sean conservados, y de la necesidad de combatir las especulaciones acerca de los hacedores de la evidencia arqueológica; en fin, doña María Eugenia ya en los años sesenta planteaba preocupaciones que aún son nuestras preocupaciones.

Un texto es un producto socio-cultural que refiere una sociedad, una época, una mentalidad o ideología. El texto comentado señala, con toda claridad, la ubicación hecha por las autoras sobre la obra de doña María Eugenia. De forma respetuosa, informada y reflexiva, se aborda una obra diversa en términos temáticos, rica en datos sustantivos, propia de un momento histórico y de concepciones teóricas determinadas; las escritoras establecen un diálogo con esa producción desde una perspectiva teórica-histórica; y si bien debe haber una distancia con respecto a esos enfoques utilizados (descripciones de las personas y de las comunidades, utilización de datos del censo, entrevistas y observación participante, comunidades en contextos determinados, chamanismo, método comparativo, referentes asumidos de la obra de Claude Lévi-Strauss, Mary Douglas, Víctor Turner), ellas abordan los escritos de la profesora Bozzoli con cuidado, atemperadamente y con un gran respeto académico.

Otros aspectos valorados en el texto son las exigencias, retos y desafíos enfrentados por las mujeres quienes se habían decidido por la investigación antropológica, cuyo requerimiento central era el trabajo de 
campo. Nos podemos imaginar lo complicado y difícil que debió de haber sido para doña María Eugenia internarse en los territorios indígenas y campesinos por largos períodos de tiempo, sobrellevar largas y extenuantes jornadas de trabajo, caminatas por lugares difíciles, comida limitada y, sobre todo, el convencer a los hombres de que una mujer podía hacer ese trabajo y hacerlo bien, como fue el caso de nuestra autora; desde luego contando siempre con el apoyo importante e insustituible de su familia.

Para finalizar, deseo indicar que el texto que hoy comentamos es un medio idóneo no solo para acercarnos a la obra de María Eugenia Bozzoli Vargas, sino también para acceder a una discusión teóricometodológica disciplinaria, a una información precisa y pertinente acerca de sitios arqueológicos, petroglifos, cerámica, característica del cambio rural urbano, discusiones acerca del medioambiente, simbolismo y medicina talamanqueña, zonas de refugio, fronteras agrícolas, huaquerismo y comercio de evidencia arqueológica. Vale la pena leer con avidez y entusiasmo este trabajo, dejarse llevar por esos rincones de la Patria que doña María Eugenia visitó por tantos años, enfrentando obstáculos, investigando y dando a conocer sobre la diversidad cultural y étnica que nos caracteriza, excavando literalmente nuestra identidad, formando personas en Antropología y en Arqueología, creando las condiciones infraestructurales para investigar, para ejercer la docencia, para hacer acción social (debe recordarse que doña "Maruja" fue Vicerrectora de Acción Social y Presidenta del Consejo Universitario de la Universidad de Costa Rica). La obra es rica en información científica, en análisis teórico-metodológico, en referencias históricas de la disciplina antropológica, mas, sobre todo, es invaluable porque aborda, a partir de los escritos, a una persona íntegra, comprometida, amante de su país y preocupada y ocupada por sus problemáticas y por la calidad de vida de su gente; atenta siempre a lo que pasa con la cultura; sencilla y humilde, dispuesta siempre a colaborar, aún a contrapelo de su salud.

Las autoras logran construir una obra de gran valor, nítida, bien documentada, reflexiva y de agradable lectura; no podía ser diferente porque ellas son así, valiosas, valientes, comprometidas, trabajadoras y por siempre antropólogas. Muchas gracias por esta obra. 